\title{
CLAUDINA, DEL RECUERDO A LA VIDA
}

\author{
Luis Mariano Esteban Martín \\ Madrid
}

\section{A mi mujer María Victoria y a mi hija Gala}

Cuando en 1547 aparecía la primera edición de la Tragedia Policiana, de Sebastián Fernández, el ciclo celestinesco estaba perfectamente consolidado merced a las obras de Feliciano de Silva, Gaspar Gómez de Toledo y Sancho de Muñón, pero al mismo tiempo estos autores, por diversas razones, habían acabado con el mecanismo de relación cíclica más fértil: la presencia en sus obras de Celestina o de una tercera relacionada directamente con ella en Celestina. Así, tras la resurrección de la vieja alcahueta en la Segunda Celestina, Gaspar Gómez de Toledo acaba definitivamente con ella en su Tercera Celestina y Sancho Muñón hace lo propio con Elicia en su Tragicomedia de Lisandro y Roselia. Estos hechos obligaron a Sebastián Fernández a aguazar el ingenio retomando como mediadora de los amores de Policiano y Philomena a Claudina, la amiga y maestra de Celestina y madre de Pármeno en el texto rojano, de manera que la Tragedia Policiana, a diferencia del resto de continuadores de Celestina, transcurre en un tiempo anterior a la obra modelo.

En un viejo trabajo analicé las constantes alusiones que aparecen en la Tragedia Policiana entroncando a Claudina con Celestina, ${ }^{2}$ de modo que las páginas que prosiguen pretenden abordar la personalidad y funcionalidad que tiene en esta obra la que en Celestina no es más que un recuerdo constante de la alcahueta y cuya función en Celestina, especialmente como elemento para convencer a Pármeno, tan bien fue expuesta por Snow. ${ }^{3}$

Ya en el título de la obra se nos hace una presentación sucinta de quién es este personaje que mediará en los amores de Policiano y Philomena: "la diabólica vieja Claudina. Madre de Parmeno y maestra de Celestina."4 Así pues, Claudina es presentada, dejando al margen su relación con los personajes de Celestina, como tercera y relacionada con la magia.

La tercería, amén de los antecedentes literarios, estaba perfectamente vigente en la España del XVI, como bien recogía, entre otros, Antonio de Guevara. ${ }^{5}$ Ahora 
bien, lo que aquí nos interesa analizar es la función que la tercera tiene en la obra en cuestión y la importancia de la magia.

Como su amiga y "discípula" Celestina, Claudina es una profesional de la tercería, de modo que las palabras de Lida de Malkiel sobre Celestina ("para Celestina la tercería no es el último recurso contra la miseria de la vejez, sino una vocación") ${ }^{6}$ cuadran a la perfección con Claudina y no se contradicen con las palabras que la alcahueta dice a Florinarda, madre de Philomena, en defensa del matrimonio (XI,164), ya que lejos de ser, como anotó Lida, una forma de "asomar incongruentemente la moral del autor, ${ }^{7}$ constituyen un modo hábil de la alcahueta para introducir en la conversación amorosa a la joven Philomena sin que su madre tenga sospechas.

Este oficio de tercera, además de sus relaciones con la magia, lleva aparejadas prácticas como la de zurcidora de virgos (IX, 150), perfumera, partera (VI, 134), así como otros tales oficios como vendedora de telas y baratijas, que eran una forma de encubrir, como ha señalado Deleito y Piñuela, su oficio real de alcahueta. ${ }^{8}$

Por lo que respecta a su actividad como perfumera, hay que recordar la amplia difusión de la cosmética, especialmente femenina, como lo demuestra la crítica constante a los afeites que hicieron distintos moralistas como fray Luis de León, que dedica el capítulo XI de La perfecta casada a atacar esta costumbre, llegando a decir que "las floridas pinturas del rostro son señal y pregón de ramera." Así pues, el oficio de perfumera, presente también en todas las obras del ciclo, se convierte en consustancial a la definición de la alcahueta y aparecerá en obras posteriores, como en la Guiay avisos de forasteros que vienen a la Corte, de Liñán y Verdugo, quien al describir a doña Pastaña aludirá a los polvos, aguas y demás enseres cosméticos. ${ }^{10}$

Por lo que respecta a su oficio de partera, éste aparece en relación con las prácticas médicas del momento. Luis García Ballester ha señalado como en el siglo XVI seguia perviviendo la tradición médica greco-árabe, practicada básicamente en las morerías, con la tradición latina, practicada por los médicos universitarios. " Estos médicos universitarios seguían un proceso de formación eminentemente teórico que, además, no era imprescindible para el ejercicio de la profesión, ya que mediante el título de bachiller, otorgado a través de unos estudios previos a los médicos universitarios denominados Artes, se podía acceder al ejercicio profesional. ${ }^{12}$

Ahora bien, junto a esta práctica legal de la medicina se sitúan prácticas médico-supersticiosas, especialmente entre los moriscos, y prácticas médicas apoyadas en la astrología, la medicina natural, la magia, etc., que planteaban considerables controversias. Es en este submundo de la medicina en donde se insertan las prácticas médicas de Claudina, tanto en lo referente a su actividad como partera como en lo referente a los polvos que ofrece a Cornelia para encarnar los dientes (XVII, 201), o las plantas que aconseja a Orosia como purgantes (XVII, 201), y bajo esta perspectiva hay que entender el que Florinarda consienta que la alcahueta visite a su hija, que se 
encuentra enferma (XI, 166), y que cuando Theophilón, padre de Philomena, le pregunte a Claudina el motivo de su visita, ésta le responda que vino a "ensalmar a mi señora Philomena, que se siente mala de la cabeça" (XVII, 203). No obstante, frente a Celestina, cuya botica, estudiada por Laza Palacio, ${ }^{13}$ contenía productos que aparecerán mencionados en formularios de boticarios en siglos posteriores como la Práctica de boticarios, guia de enfermos y remedio de pobres, de Pedro Gutiérrez, ${ }^{14}$ la actividad médica de Claudina y la relación de productos es menor.

Ahora bien, estos oficios son colaterales a su auténtica profesión: la tercería, y de ahí que sea a este oficio al que constantemente aluda Claudina así como a la profesionalidad con que lo ejerce. A Salucio y Solino les señala que "hay tan pocas que algo sepan deste mi oficio, que a quien más pensays que entiende, le falta más para discípula que tiene de sobra para buena maestra" (IX, 149). El resto de personajes de la obra le reconocen su profesionalidad como tercera, como lo demuestran las palabras de Salucio al aludir a la vieja como "examinada maestra" en el arte de la alcahuetería (VI, 132), y en relación con esta profesionalidad está la gran cantidad de trabajos que tiene, tal y como aparece en el acto XIII, donde Silvanico ha de esperar a poder hablar con ella a que despache al despensero y al paje del Duque, de ahí las palabras de Claudina disculpándose ante Silvanico por su tardanza: "Tengo muchos negocios..." (XIII, 178). Además, no olvidemos que a su mucho trabajo, fruto de su bien hacer, obedece que pidiese ayuda a Celestina (IX, 151).

En relación con esto está su preocupación por la honra en su oficio. Rubio García ha señalado como en Celestina se anticipa un concepto de honra, extendido posteriormente en el Siglo de Oro, "desligado de toda ética (...), se fundamenta (...) en la opinión y estimación ajenas. Bajo este condicionamiento, tan honrado se siente el caballero como la ramera. ${ }^{15}$ Este sentido de honra, que justifica la actitud de Celestina respecto a su oficio, ${ }^{16}$ subyace en las palabras de Claudina al acceder a correr con los distintos riesgos de su oficio para mantener su honra profesional. Así, en la primera visita a Philomena, desoye los consejos de Parmenia diciendo: "Diformes invonvenientes se me ofrecen de tu aviso y no puedo bolver atrás en este camino, porque tengo prometido el acometimiento y aun dada mi palabra de la victoria. Notable deffecto es la inconstancia y tanto que se tiene por indicio de locura" (XI, 161). Poco después, en su monólogo camino de la casa de Philomena, al sopesar los distintos peligros que de su embajada pueden producirse, expresa: "Si voy allá, a peligro pongo mi vida. Si dexo de cumplir lo prometido, no puedo escapar de muerta o apaleada, y lo que es más de estimar, el mal nombre que de falsaria puedo cobrar. Pues si el crédito pierdo, acabada es la grangería; ora venga lo que viniere, que aparejado está donde cayga" (XI, 162).

Por lo tanto, estamos ante una profesional de la tercería, que como tal vive de sus oficio y por el mismo recibe una paga: diez doblas inicialmente (VIII, 148) y quinientas monedas de oro con posterioridad (XVIII, 209). 
Para la realización de su oficio, Claudina se vale del perfecto conocimiento que tiene de su entorno. Conoce a Solino (IV, 124), a Policiano (IV, 125), a Florinarda y su casa (XI, 166), e incluso posee un "registro" donde se recogen sus posibles clientes (IV, 125), o aquellos con los que ya tenía trato, que donará a Celestina antes de morir: "Cata aquí, comadre, una matrícula y memorial en que hallarás ciento y quarenta y dos moças que a mí estavan encomendadas y setenta y ocho despenseros a quien estava obligada a proveer, y veinte y cinco virgos que tengo que remediar" (XXVII, 264).

Frente a lo ocurrido en las obras de Silva y Gaspar Gómez, donde la entrada de la alcahueta en la mediación de los amores de los protagonistas no está claramente justificada, en la Tragedia Policiana, más en consonancia en este aspecto con Celestina, la entrada de Claudina se resuelve con más acierto. Cuando el desasosegado Policiano pide consejo a Solino para poder hablar a Philomena, éste le propone que le envíe una carta $(I, 110)$. Ahora bien, Solino recapacita sobre los peligros que pueden sobrevenirle al llevar la carta y, aconsejado por Salucio, acuerda que la carta la lleve Silvanico, el cual mantiene relaciones con la criada de Philomena (II, 112). Posteriormente, Solino, sin consultar a su amo, ofrecerá el caso a Claudina para evitarse complicaciones (IV, 125), pero este ofrecimiento se produce ante una hábil insinuación de la propia alcahueta: "no sé yo si la dama le ha seydo favorable, que días ha grandes que le tengo en mi registro y aún estoy espantada cómo no ha venido a mis manos" (IV, 125).

Aparentemente, Sebastián Fernández tampoco ha sabido resolver satisfactoriamente la razón por la que el enamorado ha de dar entrada a una tercera profesional. Sólo la impaciencia del enamorado, común a todos sus antecesores, parece justificar la aceptación de una alcahueta profesional, con los oficios que lleva aparejados, y de ahí la duda del enamorado; "Pues dime la verdad. Solino, ¿qué de veras te paresce a ti ser necessario dar parte a esta muger?" (VI, 134-135).

Sin embargo, hay que hacer una precisión. Señala Cardini que "la clientela del brujo y la hechicera pertenecía a las más variadas capas sociales, pero se homogeneizaba en el hecho de tener necesidades y deseos inconfesables. ${ }^{17}$ Es decir, distintamente a Silva y Gaspar Gómez, cuyos enamorados aceptarán el matrimonio como solución, la entrada de la tercera en la Tragedia Policiana viene dada por la marginalidad social, la deshonestidad e ilicitud con que Policiano concibe su amor, el cual persigue la consecución física de Philomena y rechaza los convencionalismos sociales. En una palabra, la entrada de la alcahueta se justifica por la concepción amorosa que se plantea en la obra. Una concepción que si bien se formula bajo los convencionalismos del amor cortés por parte de Policiano -se siente inferior a la amada (I, 104), no le importa morir en el servicio al amor $(I, 105)$, etc.- tiene como finalidad la posesión física de Philomena dentro de una concepción del amor como absoluto, sin más fin que su resolución en sí mismo y por tanto alejado de un planteamiento matrimonial. $\mathrm{Y}$ es esta concepción la que justifica la entrada de 
Claudina, una mediadora en amores ilícitos.

En el acto VIII, Claudina se hace cargo de los amores de Policiano, señalando que posee "algunos instrumentos que para entender en esta cura son necesarios" (VIII, 147), con lo que Claudina está apuntando a sus artes de hechicería. En el título de la obra se alude a Claudina como "diabólica vieja," Solino la define, junto con otros oficios, como "la mayor hechicera que se ha hallado dende el principio del mundo hasta oy. Tiene tanta abilidad en caso que requieran artificio sobrenatural que a todo el infierno junto trae consigo con sola su boz" (VI, 134). Dorotea alude a ella como "vieja hechizera" (XV, 189), "más diabólica que humana" (XV, 191).

En definitiva, la tercería, como desde la antigüedad, aparece íntimamente relacionada con prácticas de magia amorosa, ya que a las terceras profesionales no se las buscaba para utilizarlas como recadras de los amores, sino como profesionales en la realización de la philocaptio, es decir, en la creación de una pasión amorosa a través de medios mágicos tal y como había explicitado en su Formicarius Juan Nider (1435), al definir la philocaptio de acuerdo a tres modos: "Aliquando ex sola incantela oculorum; aliquando ex tentatione demonum tantum; aliquando vero ex maleficio necromanticorum similiter et demonum, ${ }^{18}$ siendo el tercer caso el que contaba con la participación directa de la hechicera.

No es el momento de analizar aquí la realidad histórica de estas prácticas de pbilocaptio, pero sí de ver la función que tienen en el desarrollo de la trama de la Tragedia Policiana, señalando de antemano que Claudina es una hechicera y no, como ha querido ver Garrosa, apoyándose en las palabras de Celestina a Pármeno en el auto VII de Celestina, una bruja. ${ }^{19}$ Ciertamente, en la época no quedan claras las diferencias entre la brujería y la hechicería. Maravall alude a la brujería como "un culto demoníaco, de carácter colectivo y sobrenatural" y a la hechicería como "manipulación de una serie de cosas que se supone ejercen una acción sobre las fuerzas ocultas que se hallan en la Naturaleza. ${ }^{20}$ En la medida en que Celestina no participa en rituales colectivos, misas negras o invocaciones demoníacas de magia negra no podemos considerarla bruja. En este sentido, una vez más, las continuaciones de Celestina arrojan luz. A lo que se me alcanza, ninguna obra del ciclo alude a las terceras como brujas, sino sistemáticamente como hechiceras. Pero aún hay más. En el episodio citado de Celestina, la vieja le dice a Pármeno, aludiendo a las cuatro veces que detuvieron a Claudina, que "aun la una le levantaron que era bruxa. ${ }^{21}$ Russell anotó, apoyándose en los comentarios legales que aporta la Celestina comentada, que Claudina inicialmente fue concebida como bruja y que "por razones que ingnoramos" Rojas modificó esta configuración. ${ }^{22}$ Las palabras de Celestina se producen dentro de un contexto de demostración que hace a Pármeno del conocimiento que tiene de su madre Claudina, para lo cual recuerda diversos episodios como el del ahorcado, episodio que gozó del favor de los continuadores, como lo demuestra su presencia en la Segunda Celestina, al recordar Celestina sus idas a la "horca del Teso" con Claudina, ${ }^{23}$ o en la misma Tragedia Policiana (IX, 150), no aludiéndose en ninguna de 
estas dos obras a Claudina como bruja.

Quizá convenga para zanjar este tema analizar las palabras de Celestina a Pármeno en Celestina dentro del contexto en que se producen, porque de ello se desprende, en mi opinión, algo más simple que lo que apunta Russell. Al aludir Celestina a que a Claudina "le levantaron que era bruxa" está entendiendo el verbo en el sentido, recogido por Covarrubias, de "levantar falso testimonio"; es decir, Celestina deja sentada la falsedad de esta acusación y así lo entendieron Silva y, sobre todo, Sebastián Fernández, de ahí que pese a retomar el episodio no utilicen en ningún caso el término bruja. De acuerdo con esto, la hipótesis de Russell me parece que olvida el contexto en que se produce la frase, mientras que los continuadores, lejos de plantearse disquisiciones legales, sí tuvieron presente y entendieron a la perfección el contexto de la frase de Celestina.

Una vez sentada esta cuestión, volvemos a nuestro propósito inicial para acercarnos a la funcionalidad de la magia en la Tragedia Policiana. Ana Vian ha sintetizado el status questionis para Celestina concluyendo con que "la magia es (elemento integral) porque afecta a las principales dramatis personae y no sólo a la tercera. ${ }^{24}$ Lo que nos encontramos en la Tragedia Policiana es que Claudina, tras encargarse de los amores de Policano y. Philomena, pide a Libertina los aparejos necesarios para hacer un conjuro en el que utiliza todos los elementos habituales -un aro de cuba, candelas, soga del ahorcado, etc. (IX, 154). El hilado utilizado por Celestina para su conjuro, de amplia tradición en la magia, ${ }^{25}$ es sustituido por un anillo en la Tragedia Policiana, elemento de no menos tradición mágica, por cuanto había la creencia de que hechiceros y nigrománticos poseían demonios en anillos y redomas para utilizarlos en su favor. ${ }^{26}$ Stamm ha señalado, refiriéndose a Celestina, que ésta no se conforma con realizar un filtro amoroso, sino que desea "la satisfacción personal del dominio y control sobre Melibea, ${ }^{27}$ palabras que bien pueden aplicarse a Claudina.

Realizado el conjuro, Claudina manifiesta su confianza (IX, 155) y se encamina hacia la casa de Philomena. Ahora bien, antes de ser recibida por Philomena, ésta ha tenido noticia de la carta de Policiano, en la que éste le expresa su pasión ( $\mathrm{X}$, 157). Philomena rechaza la declaración de Policiano con palabras muy similares a las de Melibea: “¿Qué atrevimiento es tan vano penssar alguno que en amor deshonesto yo ocupe mi entendimiento" $(X, 158)$, pero oculta la carta a su padre $(X, 159)$.

Claudina llega a la casa de Philomena para vender "franjuelas y cabeçones" (XI, 162) y es recibia por Florinarda sin ningún tipo de inconveniente, pues aunque pregunta a Dorotea “¿Con qué viene agora el diablo?" (XI, 163), Dorotea le ha indicado con anterioridad a Florinarda que ha preguntado por ella (XI, 163). Pero lo esencial de esta primera visita de Claudina es que Philomena, tras haber leido la carta de Policiano, señala que ha sentido "un dolor en este lado yzquierdo" (XI, 167), para cuyo remedio le entrega la vieja el anillo. En este sentido, teniendo en 
cuenta la relación de la frase de Philomena con el amor, bien podría entenderse que el cambio de actitud de la doncella respecto a Policiano no es debido al conjuro de Claudina, sino a la carta del enamorado, pero poco después, Philomena atribuirá directamente su pasión a Claudina, con lo que Sebastián Fernández ahonda en el valor de la magia en su obra. Posteriormente, Claudina hablará directamente de Policiano, siendo rechazada inmediatamente por Philomena.

En el acto XV, Philomena declara su pasión por Policiano a Dorotea señalando que esta pasión se ha producido "después de aquel trançe riguroso que con aquella buena vieja passé" (XV, 186). A partir de aquí la doncella muestra claramente su amor por Policiano. La pregunta que surge es la causa de este cambio repentino en Philomena; en definitiva, si es producto de la philocaptio.

A diferencia de Melibea, Philomena señala como nacimiento de su pasión el momento en que habló con Claudina: "Amiga Dorotea, después de aquel trançe riguroso que con aquella buena vieja passé, ningún momento ha dejado mi mal de me poner en el último término de la vida" (XV,186). De modo que bien podemos afirmar que estamos ante un evidente caso de philocaptio. En este sentido, los personajes de la obra nos confirman este hecho. Así, Dorotea, tras la declaración de su señora, dice: “(...) a mi parescer, esta vieja hechizera, tan dañosa entre las donzellas nobles como el lazo del paxarero entre las aves, ni el cielo la avía de alumbrar ni la tierra substentar" (XV, 189). Asimismo, Solino, que en el acto VI le había expuesto a Policiano las habilidades hechiceriles de Claudina, no duda en señalar como causa del éxito de Policiano "la Claudina con conjuros" (XXVIII, 268). Por su parte, Claudina no duda en achacar su éxito al anillo: "Bien pensara la golosita de Philomena gozar de la possessión de mi anillo" (XVIII, 205). En definitiva, como ha señalado Vian, en la medida en que los personajes tienen conciencia de la existencia de la magia amorosa $y$, sobre todo, creen en su eficacia, la magia se convierte en un elemento esencial en las obra. ${ }^{28}$

Todavía en el acto XVI la vieja pedirá diversos aparejos para realizar un filtro que acerque a Dorotea a Silvanico, aun cuando este conjuro está injustificado pues desde el principio de la obra Silvanico se nos presenta como enamorado de Dorotea y aceptado por ella.

Una vez que Philomena ha manifestado su amor por Policiano, manda llamar a Claudina. En esta segunda visita Philomena entregará una carta a la alcahueta, donde cita a Policiano, cuyo contenido desconoce Claudina (XVI, 203), de ahí la impaciencia de la vieja ante Policiano por saber dicho contenido: "Lee ya, señor, que me tienes colgada de la lengua" (XVIII, 207-208). En este momento la alcahueta se ha convertido en una mera correveidile que incluso desconoce el contenido de su embajada, lo que supone una considerable desvirtuación con respecto a Celestina.

Tras la cita (a través de la carta) de Philomena con Policiano, el papel de la 
vieja se da por concluido, recibiendo por ello "quinientas monedas de oro" (XVIII, 130) y la promesa de otras dádivas. A partir de aquí, su presencia en la obra se concentra en una serie de episodios rufianescos que ejemplifican el mundo en que se desenvuelve. En el acto XXV, la vieja se encamina a la casa de Philomena para recobrar el anillo, lo que se convertirá en una trampa para que Silverio y Pámphilo ejecuten a la vieja siguiendo la orden de Teophilón, acto XXVI. Moribunda, Claudina hace llamar a Celestina y en su última voluntad la hace heredera de un conjunto de útiles hechiceriles (los mismos que utilizará Celestina) y le encomienda la tutela de Pármeno (XXVII, 263-264).

Mientras que la vieja Celestina muere a manos de Sempronio y Pármeno como consecuencia de su negativa a compartir la ganancia obtenida de manos de Calisto, la muerte de Claudina es causa directa del planteamiento de honra expuesto reiteradamente por Theophilón. El punto en común con la muerte de Celestina es, al igual que la muerte de Policiano, la ausencia de confesión. Que de ello se pueda desprender una valoración moral global de la obra o un mero topos literario es algo ajeno a estas páginas, pero, en cualquier caso, muestra, al igual que en la vieja Celestina, la estrecha relación existente entre el mundo de la superstición y hechicería y la religión, tal y como ha analizado, para el caso de la Tragedia Policiana, Finch. ${ }^{29}$

La Claudina re-creada por Sebastián Fernández servirá para que Alonso de Villegas entronque con ella a la alcahueta Dolosina de su Comedia Selvagia, ya que es hija de Parmenia y por tanto nieta de Claudina. ${ }^{30}$ Es más, cuando Dolosina vaya camino de la casa de Polibio recordará que "en vn caso semejante al en que agora voy dexo mi abuela Claudina la vida por las costillas en manos de los criados de Theophilón, ${ }^{31}$ lo que supone una clara aceptación del recurso de Sebastián Fernández por parte de otro autor integrante del ciclo.

\section{$* * *$
Notas}

'Ver mi "Muerte, resurrección y muerte de Celestina: Tres autores ante un personaje," Cuadernos para la investigación de la literatura bispaánica 15 (1992): 137-143.

${ }^{2}$ L. M. Esteban Martín, "Huellas de Celestina en la Tragedia Policiana de Sebastián Fernández," Celestinesca 13.1 (mayo 1989): 31-41.

${ }^{3} \mathrm{~J}$. T. Snow, "Celestina's Claudina," Hispanic Studies in Honor of Alan D. Deyermond: A North American Tribute,ed. J. S.Miletich (Madison,WI: HSMS,1986), pp. 257-277.

${ }^{4}$ Para las citas sigo mi tesis doctoral "Edición y Estudio de la Tragedia Policiana, de Sebastián Fernández" (Universidad Complutense de Madrid [colección Tesis Doctorales, no. 388/92], 1992).

${ }^{5}$ Antonio de Guevara, Menosprecio de Corte y Alabanza de Aldea, ed. Asunción Rallo, (Madrid: Cátedra,1984), p. 210.

${ }^{6}$ M. R. Lida de Malkiel, La originalidad artística de La Celestina (BuenosAires: EUDEBA, $1970^{2}$ ), p. 515. 
7 Originalidad, 579.

${ }^{8}$ J.Deleito y Piñuela, La mala vida en la España de Felipe IV, (Madrid: Alianza,1987), p. 70 .

${ }^{9}$ Fray Luis de León, La perfecta casada, ed. Mercedes Etreros, (Madrid: Taurus, 1987), p. 139.

${ }^{10}$ Ed.de Edisons Simons, (Madrid: Editora Nacional,1980), p. 158.

"Luis García Ballester, Historia social de la medicina en la España de los siglos XIII al XVI (Madrid: Akal,1976), p. 40.

${ }^{12}$ Marcelino V.Amasuno, "Literatura médica en la Universidad de Salamanca durante la épocoa de los Reyes Católicos", en M. Criado de Val (dir.), Literatura Hispánica. Reyes Católicos y Descubrimiento, (Barcelona: PPU, 1989), p. 76.

No obstante, pese al carácter eminentemente teórico de las enseñanzas médicas universitarias, Universidades como la de Valencia, recogiendo las ideas del De bumani corporis fabrica, de Andrés Vesalio, llevaron a cabo una imporante actividad en la disección de cadáveres [Antonio Prieto,La prosa española del siglo XVI, I, (Madrid: Cátedra, 1986), p. 289].

${ }^{13}$ Modesto Laza Palacios, El laboratorio de Celestina, (Málaga: Antonio Gutiérrez, 1958). 268.

${ }^{14}$ José María Fuentes Aynat, “La botica de la Celestina”, Medicamenta 44 (1951):

${ }^{15}$ Luis Rubio García, Estudios sobre 'La Celestina', (Murcia: Universidad, 1970), p.70.

${ }^{16}$ Gustavo Correa, "Naturaleza, religión y honra en La Celestina," Publications of the Modern Language Association, 77 (1962): 15-16.

${ }^{17} \mathrm{~F}$. Cardini, Magia, brujeria y superstición en el Occidente medieval, (Barcelona: Península, 1982), pp. 117-118.

${ }^{18}$ Citado por P. M. Cátedra, Amor y pedagogia en la Edad Media, (Salamanca:Universidad, 1989), p. 91.

${ }^{19}$ Antonio Garrosa Resina, Magia y superstición en la literatura castellana medieval, (Valladolid: Universidad,1987), p. 565.

${ }^{20} \mathrm{~J}$. A.Maravall, El mundo social de La Celestina' (Madrid: Gredos, $1976^{4}$ ), p. 150.

${ }^{21}$ Cito por la ed. de D. S. Severin (Madrid: Cátedra, 1988), p. 198.

${ }^{22}$ P. E. Russell, Temas de La Celestina' y otros estudios. Del Cid al Quijote, (Barcelona: Ariel, 1978), pp. 330-331.

${ }^{23}$ Cito por la ed. de C. Baranda (Madrid: Cátedra, 1988), p. 487.

${ }^{24}$ Ana Vian Herrero, "El pensamiento mágico en Celestina, instrumento, lid o contienda," Celestinesca 14.2 (noviembre 1990), p. 70.

${ }^{25}$ David T.Sisto, "The String in the Conjuration of La Celestina and Doña Bárbara," Romance Notes, I (1959-1960): 50-52.

${ }^{26}$ F.J.Flores Arroyuelo, El diablo en España, (Madrid: Alianza,1985), p. 75.

${ }^{27}$ James R.Stamn, La estructura de La Celestina'. Una lectura analitica (Salamanca: Universidad 1988), p. 87.

${ }^{28}$ Vian Herrero, "El pensamiento mágico," p. 68.

${ }^{29}$ Patricia S.Finch, "Religion as Magic in the Tragedia Policiana," Celestinesca 3.2 (1979): 19-24. Y de la misma autora, Magic and Witchraft in the 'Celestina' and Its Imitations,(Tesis doctoral) Catholic University, 1981.

${ }^{30}$ Alonso Villegas, Comedia Selvagia (Toledo 1554), II, III, fo.xxxiii(v)-xxxiiii(r).

${ }^{31}$ Villegas, Comedia Selvagia, III, III, fo.xliii(r). 


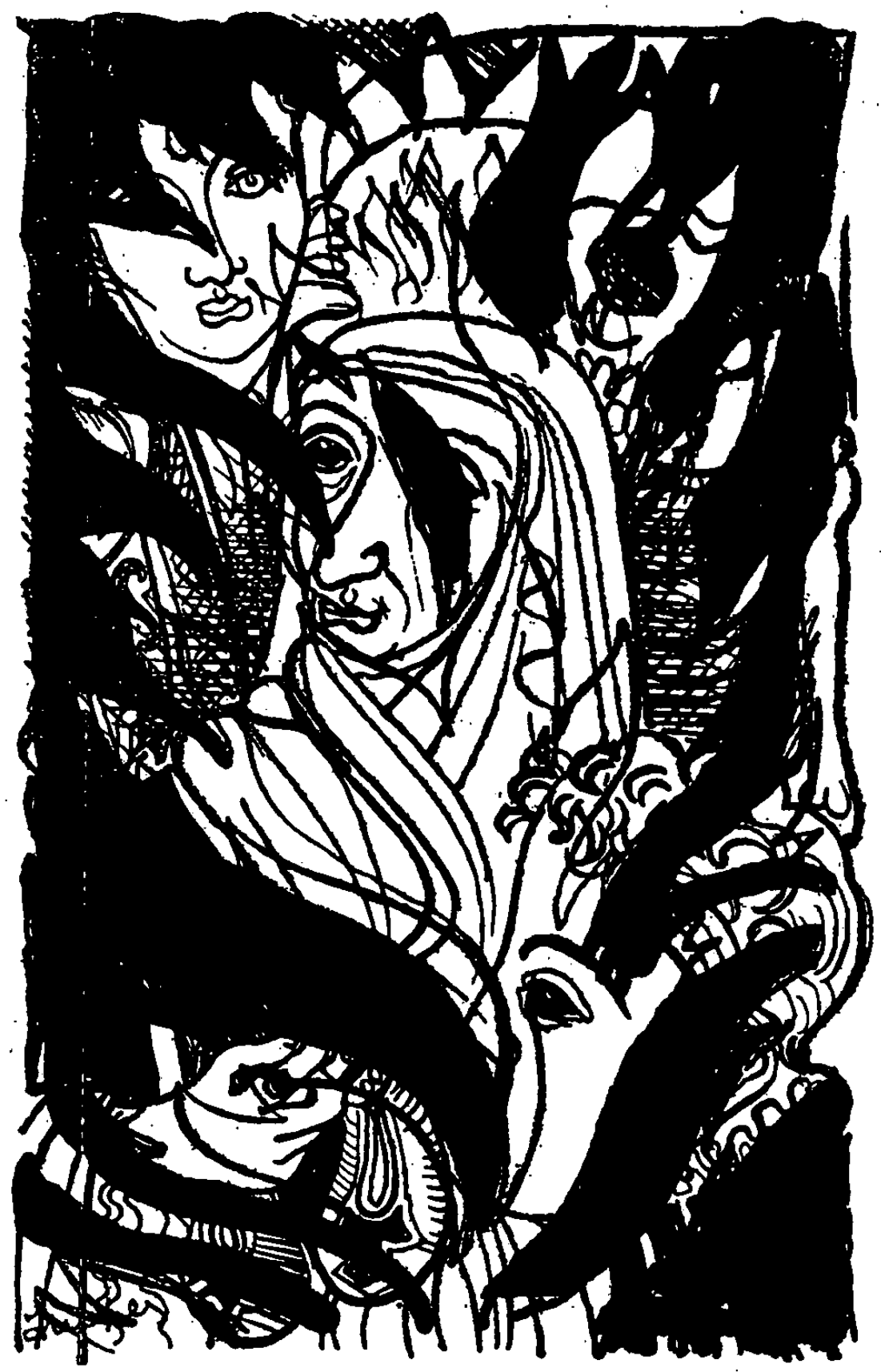

Frontispicio de Jean Mohler. Para la reimpresión de la traducción francesa de Germond de Lavigne por "Les Compagnons du Livre" 